\title{
A Review of Kinetics of Nanoparticulated Delayed Release Formulations
}

\section{Roli Jain and Archna Panday*}

Department of Chemistry, Dr. Hari Singh Gour University, Sagar, 470003 (M.P), India

\begin{abstract}
The history and development of chemical kinetics gives a fascinating insight into the way in which theory and experiment can become mutually interdependent. Kinetics plays a key role in the study of what the body dose to a drug so these areas of study move towards pharmacokinetics. In the last decade or so there has been a vast upsurge of interest in the physical mechanism of reaction.
\end{abstract}

The United States Pharmacopeia (USP) defines delayed-release tablets as enteric-coated to delay release of the medication until the tablet has passed through the stomach. To prevent the drug from being destroy or inactivate by gastric juices or where it may irritate the gastric mucosa.

The suitability of several equations which have been reported in the literature to define drug release mechanism was tested with respect to the release data. To analyze the mechanism of drug release from the matrix tablet data obtained from the drug release studies were analyzed according to zero order model, Higuchi model, and Korsmeyer - Peppas model respectively.

Keywords: Delayed release formulation; Controlled release; Enteric coated; Korsmeyer - Peppas; Higuchi model; Nanoparticle

\section{Introduction}

The history and development of chemical kinetics gives a fascinating insight into the way in which theory and experiment can become mutually interdependent. Arrhenius confers the basics of the subject as a rigorous science when he postulated that not all molecules can react; only that molecule reactant which has a certain minimum energy, this energy has been called activation energy. The fraction of reactant molecules which possess this critical energy is calculated from the Maxwell Boltzmann distribution which is the foundation of the most theoretical approaches [1,2].

In the last decade or so there has been a vast upsurge of interest in the physical mechanism of reaction. This is a description at an even more fundamental microscopic level than the molecular level of the chemical mechanism. A whole new field of kinetics has developed out of this interest, and the great advances in molecular beam and molecular dynamic studies reflect this interest.

Kinetics play a key role in the study of what the body dose to a drug so these areas of study move towards pharmacokinetics thus we can say pharmacokinetics is based on the study of the variation of plasma concentrations of drugs, because it is the only easily accessible parameter, before approaching it, is necessary to know the definitions of the terms usually used, in other words the study of the movement of drugs in the body, including the processes of absorption, distribution, localization in tissues, biotransformation and excretion.

Pharmacokinetics and pharmacodynamics are important fields of pharmaceutical sciences for investigating disposition profiles and the pharmacological efficacy of drugs in the body under various experimental and clinical conditions.

The United States Pharmacopeia (USP) defines delayed-release tablets as enteric-coated to delay release of the medication until the tablet has passed through the stomach to prevent the drug from being destroyed or inactivated by gastric juices or where it may irritate the gastric mucosa $[3,4]$.
The role of Nano-Technology in nano medicines gives revalutatory era in health care science. Nanotechnology changes the delayed release delivery toward to targeted delayed release delivery. The versatile approach of nanotechnology gives an immense platform for revolutionizing of medical treatment, faster diagnosis, tissue regeneration and drug delivery. Nanoparticle system provides a better penetration of therapeutic and diagnostic agent under the subject of nano articulated drug release system $[5,6]$.

The Drug release from the pharmaceutical Nano particle play a novel role to determine the biological effect of the drug thus the drug release kinetic is of very important field. The use of kinetic model is helpful in elucidating release mechanism which is true can be of use in the control of drug release. To the best of our knowledge a comprehensive kinetic representation of delayed drug release from nanoparticle for a purpose of general model has not been reported in the literature.

The literature reviewed revel that a very little work has been done for kinetic study of delayed release drugs. This work contains a detail release kinetic study of delayed release formulations. If the release kinetics of any drug is well understood then it is easy to modify the formulations.

The primary purpose of this review article is to discuss the kinetics of nanoparticulated delayed release formulations by the different reported kinetic models. Kinetics models furnish with very constructive approach in elucidating release mechanism which we can bring into play major role in control/delayed drug release.

*Corresponding authors: Archna Panday, Department of Chemistry, Dr. Hari Singh Gour University, Sagar, Madhya Pradesh 470003, India, Tel: 91-75822-65810; E-mail: prof.archanapandey@gmail.com

Received May 16, 2015; Accepted June 02, 2015; Published June 12, 2015

Citation: Jain R, Panday A (2015) A Review of Kinetics of Nanoparticulated Delayed Release Formulations. J Nanomed Nanotechnol 6: 304. doi:10.4172/2157 7439.1000304

Copyright: () 2015 Jain R, et al. This is an open-access article distributed under the terms of the Creative Commons Attribution License, which permits unrestricted use, distribution, and reproduction in any medium, provided the original author and source are credited. 


\section{Advantages of Delayed Release Formulations}

In recent years, goodish attention has been centered on the event of the new drug delivery system functions. A nanocarrier offers variety of benefits creating it a perfect drug delivery vehicle $[7,8]$.

- Nano carriers will higher deliver medication to small areas inside the body.

- Preparation of nanoparticle area unit terribly easy and its price effective on scale-up.

- Recognition of the likelihood of reattempting triple-crown medication by applying the construct and techniques of nanoparticulate delayed release drug delivery systems, including the increasing expense in delivery new drug entries to plug has inspired the event of latest drug delivery system.

- Nano particle keep protected the drug against chemical and protein degradation in biological fluid.

- Drug loading is comparatively high in NDR (Nanoparticulated delayed release) and might be incorporated in system without any chemical change this is often a crucial issue to stop the drug and increase the effectualness and bioavailability of drug [9].

- The surface properties of nanocarriers is changed for targeted drug delivery e.g. tiny molecules, proteins, peptides, and nucleic acids loaded nanoparticles aren't recognized by system and expeditiously targeted to explicit tissue sorts.

- NDR holds promise to deliver biotech medication over numerous anatomic extremities of body like blood brain barrier, branching pathways of the respiratory organ system and therefore the tight epithelia junctions of the skin etc.

- Targeted nano drug carriers scale back drug toxicity and supply additional economical drug distribution.

- Treating the accelerator deficient diseases and cancer therapies

\begin{tabular}{|l|c|}
\hline Polymer & Threshold pH \\
\hline Eudragit @ L-100 & 6.0 \\
\hline Eudragit @ S-100 & 7.0 \\
\hline Eudragit @ L-30D & 5.6 \\
\hline Eudragit @ FS-30D & 6.8 \\
\hline Eudragit @ L-100-55 & 5.5 \\
\hline Polyvirryl acetate phithalate & 5.0 \\
\hline Hydroxypropylm ethylcellulose phithalate & $4.5-4.8$ \\
\hline
\end{tabular}

Table 1: Threshold $\mathrm{pH}$ of commonly used polymers.

\begin{tabular}{|c|c|c|}
\hline Stimulus & Polymer & $\begin{array}{c}\text { Drug } \\
\text { Released }\end{array}$ \\
\hline $\mathrm{pH}$ & $\begin{array}{l}\text { Poly(methacrylic-g-ethyleme glycol) } \\
\text { (p(MMA-g-EG) }\end{array}$ & Insulin \\
\hline Electric field & Poly (methacrylie acid) (PMA) & $\begin{array}{l}\text { Pilocarpine and } \\
\text { raffinose }\end{array}$ \\
\hline Glucose concentration & $\begin{array}{l}\text { Poly (methacrylic acid-co-butyl } \\
\text { methacrylate) }\end{array}$ & Insulin \\
\hline Temperature & $\begin{array}{l}\text { Layer of Chitosan Pluronic on PLGA } \\
\text { microparticles }\end{array}$ & Indomethacin \\
\hline Morphine concentration & $\begin{array}{l}\text { Methyl vinyl ether-Co-anlydride maleic } \\
\text { copolymer }\end{array}$ & Naltrexone \\
\hline Urea concentration & $\begin{array}{l}\text { Methyl vinyl ether-Co-anhydride maleic } \\
\text { copolymer }\end{array}$ & Hydrocortisone \\
\hline
\end{tabular}

Table 2: Some Examples of Smart Polymers. is improved by higher targeting. The look of such system concerned release of drug solely at a selected site in GI track.

\section{Designing of Delayed Release Formulation}

The most crucial challenge in such drug delivery approach is to preserve the formulation throughout its passage through the abdomen or in acidic surroundings and concerning initial six meters of the tiny gut $[10,11]$.

Several reviews have been published reporting the research that has gone into the development of per orally delivered single unit colon targeted drug delivery systems. In general four primary approaches have been proposed for delayed targeted delivery namely prodrugs, $\mathrm{pH}$ depend system, time dependent system and colonic micro flora activated systems.

Most commonly studied multiparticulate systems for colon specific drug delivery include pellets, granular matrix, beads microspheres and nanoparticles $[12,13]$.

The $\mathrm{pH}$-dependent systems exploit the generally accepted view that $\mathrm{pH}$ of the human GI tract increases progressively from the stomach $\mathrm{pH}$ 1-2 which increases to 4 during digestion), small intestine (pH 6-7) at the site of digestion and it increases to 7-8 in the distal ileum. Thus a dosage form that disintegrates preferentially at high $\mathrm{pH}$ levels has good potential for site-specific delivery into this region [14-16].

One of the simplest approaches for designing the delayed released systems is to formulate enteric coating has traditionally been used to prevent drug released in the upper GI tract. Enteric coating polymers are reported to have been used as both binders and as coating materials for granules. The influence of incorporating organic acids in granule matrix on drug release has also been studied. In one such study, enteric coated tablets of ibuprofen were made from enteric coated granules as well as the matrix. It was reported that incorporation of citric acid in both the enteric coated granules as well as the tablet matrix retarded the in vitro release and in vivo absorption of the drug because of the prolongation in disintegration time of the core system due to the presence of the acid [17].

The most commonly used $\mathrm{pH}$ dependent coating polymers for preoral delivery are methacrylic acid, copolymers, eudragit L-100 and eudragit S-100 which dissolve at $\mathrm{pH} 6.0$ and 7.0 respectively. The threshold $\mathrm{pH}$ of commonly employed $\mathrm{pH}$ sensitive polymer is depicted in Table 1 same example of smart polymer is given under the Table 2 [18]

\section{Role of Polymer in Preparation of Nano -Particles}

Nanoparticles have been prepared most frequency by three methods: (1) dispersion of preformed polymers; (2) polymerization of monomers; and (3) ionic gelation or coacervation of hydrophilic polymers (Figure 1).

Some drugs are unstable in certain environments, such as in plasma or in acidic conditions. Therefore, in these conditions, it is of interest

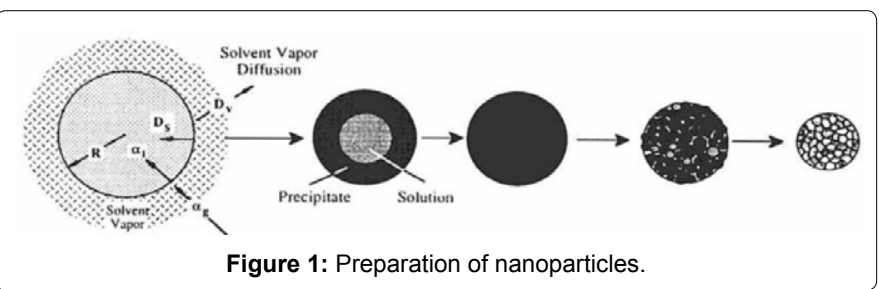


to use a polymer to protect the drug. These formulations are also used in pathologies in which the degree of compliance is low because of difficult administration or unpleasant taste of the medicine.

The polymers used in the development of drug delivery systems are designed with the capacity to form polymeric supramolecular structures (matrices and capsules), which are suitable for retaining a therapeutic agent and allow controlled release. Interactions between the polymer chains, which can be non-covalent (electrostatic and hydrogen bonds) or have covalent bonds (cross-linked polymers), confer stability to these structures. The integrity and the behavior of these structures in physiological conditions allow the controlled release of the therapeutic agent. The literature describes several mechanisms of drug release. Modulation of the chemical architecture of polymers (functional groups, interactions between chains...) can regulate the release of the therapeutic agent and thus the profile of the final formulation (delayed or immediate release, pulsatile, etc.). However, the release occurs through a combination of the three basic mechanisms mentioned previously $[19,20]$ (Figure 2).

The compound micelles composed of amphiphilic block copolymers area unit presently extensively investigated as a completely unique style of drug carrier. There tiny size and hydrophilic surface alter compound micelles to oppose the popularity by macrophages of the RES once blood vessel administration, that permits accumulation in growth and alternative pathological areas because of the thus known as EPR (enhanced permeation and retention) result. What is more, by use of stimuli-sensitive chemical compound (e.g. temperature, $\mathrm{pH}$ ) as a phase of block copolymers, it's attainable to realize a controlled release of encapsulated medication from micelles in response to environmental amendment [21-23].

Polymer area unit helpful as excipient in drug delivery formulations for variety of reasons, such as

- Through solubilization within the core of micelles or alternative forms of chemical agent self-assembled structures the effective solubility of a hydrophobic drug is also magnified

- It's hydrolytic degradation diminished, its toxicity diminished

- It's bioavailability improved

Also, the properties of the compound systems will permit advantageous effects regarding the drug release rate, extent and property of drug uptake etc.

In analogy to polymers notice broad uses in drug delivery applications. Reasons for this embrace their surface activity, that makes them economical stabilizers of mixture drug delivery systems their gel forming capability that permits several opportunities in drug delivery and their formation of self-assembly structures analogous to those, shaped by low relative molecular mass surfactants [24].
An aspect that has been highlighted in reference to the utilization of polymers in drug delivery is their biodegradation. because of chance to regulate the degradation rate of polymers over wide ranges through e.g., the chemical compound structure and composition, biodegradation has been found to produce a motivating thanks to acquire a controlled drug release over a protracted time, and to guard sensitive compounds from harsh environments, e.g., within the abdomen. Specifically, stress during this context has been placed on polymers consisting or containing, poly (lactic acid) or poly (glycolic acid) [25].

Drug molecules area unit often amphiphilic, and conjointly usually surface active. This surface activity depends on the molecular structure and therefore the balance between electricity, hydrophobic and Van der Waals forces in addition as on the drug solubility. Since the previous balance depends on the degree of charging and electricity screening the surface activity typically\} conjointly the solubility of a drug often depends on $\mathrm{pH}$ scale [26].

A notable feature of surfactants is their ability to self-associate to make micelles. Since micelles contains chemical agent molecules packing during a space-filling manner varied parameters of the chemical agent resolution amendment at the crucial micellization concentration (CMC) much drug delivery perspective, slow disintegration mechanics offers some prospects as an example [27].

- Whereas micelles shaped by low relative molecular mass surfactants disintegrate speedily.

- Block polymer micelles is also administered AN exceedingly in a very similar approach while not disintegrating over a considerable period of time. With none doubt, the slow disintegration mechanics of the micelles shaped by a minimum of some block copolymers has contributed considerably to their flourishing use in drug delivery.

- Solubilization of hydrophobic medication in block polymer Nanoparticles offers a spread of prospects.

- Through solubilization, larger quantities of meagerly soluble active substances are also incorporated in Associate in nursing solution.

- Since the water concentration within the compound core is low or terribly low, hydrolytic degradation is also reduced, thus leading to Associate in Nursing magnified chemical stability of the drug.

- Through the partitioning toward the nanoparticles, the discharge rate of the drug is also controlled.

- Nanoparticles supply opportunities to have an effect on the uptake of the drug within the body, and the solubilization of medicine they will end in diminished facet effects Associate in Nursingd a magnified potency of the drug. Conjointly within<smiles>COC(=O)OC(=O)OC</smiles><smiles>COC(=O)OC</smiles><smiles>COC(C)=O</smiles><smiles>CNC(=O)OC</smiles><smiles>COC(OC)OC</smiles><smiles>CNC(C)=O</smiles> 


\begin{tabular}{|c|c|c|c|c|}
\hline Technique & Analyte form & $\begin{array}{l}\text { Size of nominally } 10 \mathrm{~nm} \text { particles } \\
(\mathrm{nm})\end{array}$ & $\begin{array}{l}\text { Size of nominally } 30 \mathrm{~nm} \\
\text { particles }(\mathrm{nm})\end{array}$ & $\begin{array}{l}\text { Size of nominally } 60 \mathrm{~nm} \\
\text { particles }(\mathrm{nm})\end{array}$ \\
\hline ES-DMA & Dry, aerosol & $11.3 \pm 0.1$ & $28.4 \pm 1.1$ & $56.3 \pm 1.5$ \\
\hline TEM & Dry, on substrate & $8.9 \pm 0.1$ & $27.6 \pm 2.1$ & $56.0 \pm 0.5$ \\
\hline DLS (a) & Diluted liquid suspension & $13.5 \pm 0.1$ & $28.6 \pm 2.1$ & $56.6 \pm 1.4$ \\
\hline DLS (a) & Diluted liquid suspension & $13.5 \pm 0.1$ & $26.5 \pm 3.6$ & $55.3 \pm 8.3$ \\
\hline AEM & Dry, on substrate & $8.5 \pm 0.3$ & $24.9 \pm 1.1$ & $55.4 \pm 0.3$ \\
\hline SEM & Dry, on substrate & $9.9 \pm 0.1$ & $26.9 \pm 0.1$ & $54.9 \pm 0.4$ \\
\hline SAXS & Native liquid suspension & $9.1 \pm 1.8$ & $24.9 \pm 1.2$ & $53.2 \pm 5.3$ \\
\hline
\end{tabular}

Table 3: Mean diameter and expanded uncertainty average particle diameter of gold nanoparticles [adapted from, NIST certificate, 2007]. DLS results: (a) 173 ${ }^{\circ}$ scattering angle, (b) $90^{\circ}$ scattering angle. The uncertainties represent repeatability not the width of the particle size distributions [36].

the absence of drug solubilization, nanoparticles could have helpful effects e.g. as adjuvant in vaccination [28].

Through incorporation of the drug in nanoparticles, style masking is also obtained.

\section{Morphology of Drug Nano Particles}

Choice of characterization techniques for drug nanoparticles relies on the character of problems and merchandise dose kind. Some usually used stability characterization techniques square measure listed in Table 3.

Particle size and size distribution square measure the key parameters used for evaluating the physical properties of nanoparticles. A range of techniques, together with gauge boson correlation spectrometry (PCS), conjointly called dynamic light-weight scattering (DLS), optical maser optical phenomenon (LD) and colter counter, usually wont to measure the particle size and size distribution [29].

\section{Scanning Electron Microscopy}

The Scanning microscope (SEM) uses a targeted beam of highenergy electrons to come up with a range of signals at the surface of solid specimens. The signals that derive from electron-sample interactions reveal data concerning the sample as well as external morphology (texture), chemical composition, and crystalline structure and orientation of materials creating up the sample. In most applications, knowledge area unit collected over a particular space of the surface of the sample, and a 2-dimensional image is generated that displays special variations in these properties. Areas starting approximately 1 $\mathrm{cm}$ to 5 microns in width can be imaged in a scanning mode using conventional SEM techniques (magnification ranging from $20 \mathrm{X}$ to approximately $30,000 \mathrm{X}$, spatial resolution of 50 to $100 \mathrm{~nm}$ ). Accelerated electrons in associate degree SEM carry vital amounts of K.E., and this energy is dissipated as a range of signals made by electron-sample interactions once the incident electrons area unit decelerated within the solid sample. These signals embrace secondary electrons (that manufacture SEM images), backscattered electrons (BSE), diffracted backscattered electrons (EBSD that area unit wont to confirm crystal structures and orientations of minerals), photons (characteristic $\mathrm{X}$-rays that area unit used for elemental analysis and time X-rays), light (cathode luminescence-CL), and heat. Secondary electrons and backscattered electrons area unit normally used for imaging samples: secondary electrons area unit most respected for showing morphology and topography on samples and backscattered electrons area unit most respected for illustrating contrasts in composition in point samples (i.e. for speedy section discrimination). X-ray generation is made by inelastic collisions of the incident electrons with electrons in distinct orbital (shells) of atoms within the sample. Because the excited electrons come to lower energy states, they yield X-rays that area unit of a set wavelength (that is expounded to the distinction in energy levels of electrons in numerous shells for a given element). Thus, characteristic $\mathrm{X}$-rays area unit made for every part in a very mineral that's "excited" by the beam. SEM analysis is taken into account to be "non-destructive"; that is, $\mathrm{x}$-rays generated by electron interactions do not lead to volume ls of the sample, so it is possible to analyze the same materials repeatedly $[30,31]$.

\section{Transmission Electron Microscopy}

The transmission microscope (TEM) operates on constant basic principles because the microscope however uses electrons rather than lightweight. TEM use lepton as "light source" and their abundant lower wavelength create it doable to urge a resolution cardinal times higher than with a light-weight magnifier.

The melting point of nanoparticles is evidently decreased when the size is reached to the nanometer scale [32,33]. The particle size plays a crucial role in nanoparticle properties and therefore an essential task in property characterization of nanoparticles. The TEM can yield information such as particle size, size distribution and morphology of the nanoparticles. In particle size measurement, microscopy is the only method in which the individual particles are directly observed and measured morphology of the Delayed release drug will be examined by a transmission electron microscope.

The possibility for high magnifications has made the TEM a valuable tool in both medical, biological and materials research.

A "light source" at the highest of the magnifier emits the electrons that travel through vacuum within the column of the magnifier. Rather than glass lenses focusing the light within the microscope, the TEM uses magnetism lenses to focus the electrons into a very thin beam. Looking on the density of the material, a number of the electrons area unit scattered and disappear from the beam. At rock bottom of the magnifier the unscattered electrons hit a fluorescent screen, which provides rise to a "shadow image" of the specimen with its completely different components displayed in varied darkness consistent with their density. The image will be studied directly by the operator or photographed with a camera [34].

\section{Dynamic light scattering instrument}

A typical dynamic light scattering system contains of six main elements. Firstly, an optical device (1) provides a light-weight supply to illuminate the sample contained in a very cell (2). For dilute concentrations, most of the ray passes through the sample, however some is scattered by the particles among the sample in the slightest degree angles. A detector (3) is employed to live the scattered light. Within the Zetasizer Nano series, the detector position are at either $173^{\circ}$ or $90^{\circ}$, relying upon the actual model. The intensity of scattered light must be within a specific range for the detector to successfully 
measure it. If an excessive amount of light is detected, then the detector can become saturated, to beat this associate degree electrical device (4) is employed cut back to scale back to cut the intensity of the optical device supply and therefore reduce the intensity of scattering. For samples that don't scatter abundant light, like terribly little particles or samples of low concentration, the number of scattered light should be raised. During this state of affairs, the electrical device can permit a lot of optical device light through to the sample. For samples that scatter a lot of light, like giant particles or samples at higher concentration, the intensity of scattered light should be cut the suitable electrical device position is mechanically determined by the nano software package and covers a transmission vary of $100 \%$ to $0.0003 \%$. The scattering intensity signal from the detector is passed to a digital process board known as a correlator (5). The correlator compares the scattering intensity at sequent time intervals to derive the speed at that the intensity is variable. This correlate data is then passed to a pc (6), wherever the Nano software package can analyze the data the info the data\} and derive size information. Information is then passed to a computer (7), where the Nano software will analyze the data and derive size information [35].

\section{Xray diffractometry (XRD)}

As a primary characterization tool for obtaining critical features such as crystal structure, crystallite size, and strain, Xray diffraction patterns have been widely used in nanoparticle research. The patterns of pure materials, their physical mixtures, and lyophilized delayed release drug will be obtained using the Xray diffractometer with Nifiltered $\mathrm{Cu}$ K_ radiation [36-40].

\section{Kinetics and Release Behavior of Nanoparticle of Delayed Release Formulations}

The drug release analysis done by dissolution testing. Dissolution test for solid dosage forms was first introduced in United States Pharmacopoeia (USP) 18 in 1969. The rationale behind this test is that a drug should be appropriately dissolve within the gastrointestinal tract (GIT) in order to be observed dissolution hence has become the most important test to determine product quality and drug release behavior in addition to other application outlined in Figure 3.

The impact of the saturation solubility, of drug within the dissolution media is to alter the media. Generally by adjusting hydrogen ion concentration, by adding a surface-active agent or in rare case victimization non-aqueous solvents. Studied the discharge behavior of these quite drug through the study of dissolution by maintain the sink condition. The detail procedure defined in many pharmacopeias like USP, BP, etc. [40,41].

The Nernst-Brunner and Levich modifications of the NoyesWhitney equation known the vital factors to dynamics of in vivo drug dissolution. These factors embrace drug diffusivity and solubility within the GI contents, the expanse of the solid wetted by the sodium thiopental fluids and also the GI fluid mechanics $[42,43]$.

$$
\frac{\mathrm{dC}}{\mathrm{dt}}=\mathrm{AD}\left(\frac{\mathrm{C}_{\mathrm{s}}-\mathrm{C}}{\mathrm{h}}\right)
$$

Where $\mathrm{dC} / \mathrm{dt}$ is the dissolution rate, $\mathrm{A}$ is the surface area available for dissolution, D is the diffusion coefficient of the drug, Cs is the saturation solubility of the drug in the dissolution medium, $\mathrm{C}$ is the concentration of drug in the medium at time $(\mathrm{t})$ and $\mathrm{h}$ is the thickness of the diffusion boundary layer adjacent to the surface of dissolving drug.

The suitability of several equations which have been reported in the literature to define drug release mechanism was tested with respect to the release data. Some diffusion models (Korsmeyer - Pappas) are expected to be valid up to $60 \%$ cumulative drug release therefore the data for analysis were restricted to that range. To analyze the mechanism of drug release from the matrix tablet data obtained from the drug release studies were analyzed according to equation 1,2 and 3 of the zero order model, Higuchi model, and the Korsmeyer - Peppas model respectively [44-47].

$$
\begin{aligned}
& \mathrm{Mt}=\mathrm{Mo}+\mathrm{Kot} \\
& \mathrm{Mt}=\mathrm{Mo}+\mathrm{K}_{\mathrm{H}} \mathrm{t} 0.5 \\
& \mathrm{Mt}=\mathrm{Mo}+\mathrm{K}_{\mathrm{k}} \mathrm{t}^{\mathrm{n}}
\end{aligned}
$$

In all mechanism expression, Mt is that the quantity of the drug dissolved within the time $t$, Mo is that the initial quantity of the drug in desolution, blow is that the zero order release constant. $\mathrm{KH}$ is that the Higuchi rate constant, $\mathrm{Kk}$ is that the Korsmeyer release constant, and $\mathrm{n}$ is that the release exponent, that characterizes the mechanism of drug release. However, principally the Kosmeyer Peppas model is employed to investigate drug release mechanics from pharmaceutical dose forms once the release discharge mechanism isn't documented or once

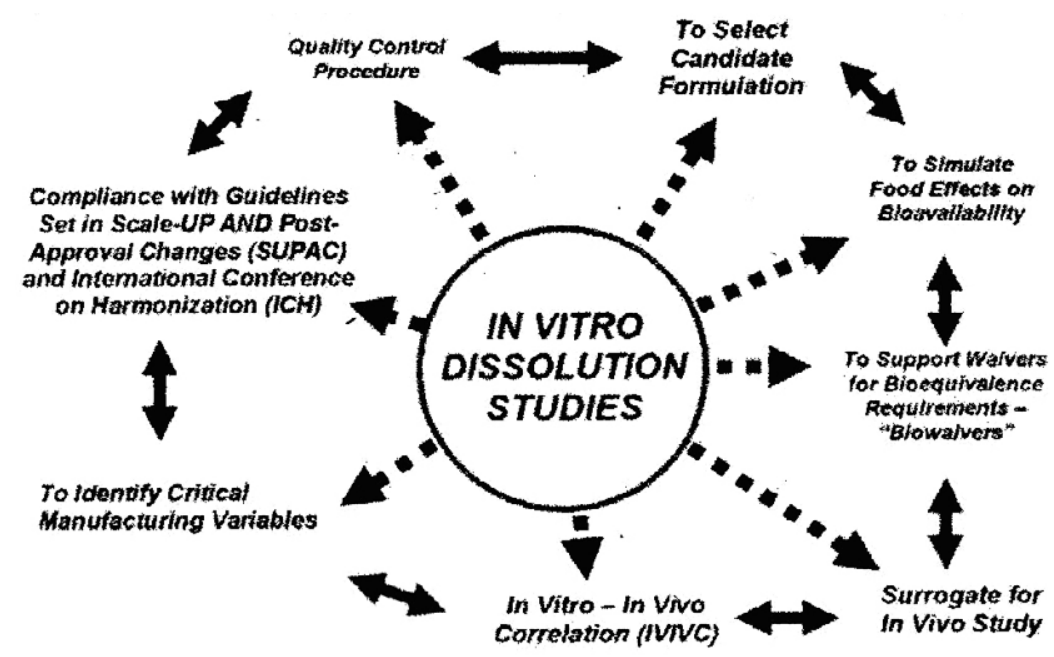

Figure 3: Drug Release Behavior 
over one form of release phenomena is concerned [41]. The easy and empirical equation in step with Kosmayer and Peppas is additionally

known as power law equation, $\frac{\mathrm{Mt}}{\mathrm{M} \infty}=\mathrm{kt}^{\mathrm{n}}$

where $\mathrm{M}_{\infty}$ is the amount of drug release after an infinite time, $\mathrm{k}$ is a constant and $\mathrm{n}$ is the exponent characterizing the release process, if a Ficklian diffusion take place $\mathrm{n}$ is equal to $0.5,0.45$ and 0.43 for a thin film, a cylinder, and a sphere, respectively when $n$ exceed these threshold nonfickian release take place eq. (5) has to be used with great care for the classification of the release nature on the basis of $n$ value. Indeed it is well known that, despite fickian diffusion in the matrix boundary condition such as the presence of a stagnant lyre or a net faced on the release surface give origin to a release kinetics characterised by a greater than 0.5. Reported different kinetics models given in table

\section{Hopfenberg model}

Hopfenberg developed a mathematical model to correlate the drug release from surface eroding polymers so long as the surface area remains constant during the degradation process [47-49]. The cumulative fraction of drug released at time $t$ was described as:

$$
\mathrm{M}_{\mathrm{t}} / \mathrm{M}_{\infty}=1-\left[1-\mathrm{k}_{0} \mathrm{t} / \mathrm{CL} \mathrm{a}\right]^{\mathrm{n}-}
$$

where $\mathrm{k}_{0}$ is the zero order rate constant describing the polymer degradation (surface erosion) process, CL is the initial drug loading throughout the system, $a$ is the system is half thickness (i.e. the radius for a sphere or cylinder), and $\mathrm{n}$ is an exponent that varies with geometry $\mathrm{n}=1,2$ and 3 for slab (flat), cylindrical and spherical geometry, respectively.

This model is used to identify the mechanism of release from the optimized oilispheres using data derived from the composite profile, which essentially displayed site-specific biphasic release kinetics.

\section{Hixson Crowell model}

Hixson and Crowell, recognized that the particles regular area is proportional to the cube root of its volume. They derived the equation:

$$
\mathrm{W}_{0}^{1 / 3}-\mathrm{W}_{\mathrm{t}}^{1 / 3}=\kappa \mathrm{t}--------(7)
$$

Where, $\mathrm{W}_{0}$ is the initial amount of drug in the pharmaceutical dosage form, $\mathrm{W}_{\mathrm{t}}$ is the remaining amount of drug in the pharmaceutical dosage form at time $t$ and $\kappa$ (kappa) is a constant incorporating the surface volume relation. The equation describes the release from systems where there is a change in surface area and diameter of particles or tablets. To study the release kinetics, data obtained from in vitro drug release studies were plotted as cube root of drug percentage remaining in matrix versus time.

Application: This expression applies to pharmaceutical dosage form such as tablets, where the dissolution occurs in planes that are parallel to the drug surface if the tablet dimensions diminish proportionally, in such a manner that the initial geometrical form keeps constant all the time [50-53].

\section{Conclusion}

The drug release kinetics give a better understanding and open the door of new era in a development field of new delayed release drug for scientist. Use of nano particles help with show poor oral bioavailability, because their absorption is kinetically limited, due to low rate of dissolution. Several low molecular weight polymers have been widely used to enhance the solubility of hydrophobic drug and the alternative used of is incorporation of drug in supramolecular assemblies such as polymeric micelles. It's a next step toward the nanotechnology.

Several study show numerous nanoparticle-based drug delivery and drug targeting systems are currently developed or under development. Their use aims to minimize drug degradation upon administration, prevent undersirable side effects, and increase drug bioavailability and the fraction of the drug accumulated in the pathological area.

Author wish that pharmaceutical drug carriers, especially the ones for parenteral administration, are expected to be easy and reasonably cheap to prepare, biodegradable, have small particle size, possess high loading capacity, demonstrate prolonged circulation, and, ideally, specifically or non-specifically accumulate in required pathological sites in the body.

In conclusion, to this, nanoscale-based delivery strategies are beginning to make a significant impact on targeting programs and also global pharmaceutical planning and marketing.

\section{Acknowledgement}

I am thankful to the department of chemistry Dr. Hari Singh Gour University india providing an opportunity to work here as a research Scholar and also thankfull to MPCOST to providing the financial help.

\section{References}

1. http://www.sriconsulting.com/CEH/Public/Reports/582.0000/

2. Knop K, Hoogenboom R, Fischer D, Schubert US (2010) Poly(ethylene glycol) in drug delivery: pros and cons as well as potential alternatives. Angew Chem Int Ed Engl 49: 6288-6308.

3. Pasut G, Veronese FM (2009) PEG conjugates in clinical development or use as anticancer agents: an overview. Adv Drug Deliv Rev 61: 1177-1188.

4. Jain R, Pandey A, Pandey SS (2009) Mechanism of Dissolution of Delayed Release Formulation of Diclofenac Sodium. Bulgarian J Chemical Edu 18.

5. United States Pharmacopoeia 32 (2012) The U. S. Pharmacopeial Convention, Rockville, Maryland.

6. Nema N, Pandey A (2011) Determination of ketoconazole in different formulations by using polymeric surfactants under the influence of Ammonium Metavanadate. Oxidation Communication 34: 98-107.

7. Mahaguna V, Talbert RL, Peter JI, Adams S, Reynolds TD, et al. (2009) Eur J Pharm Biopharm 56: 101-108.

8. Christian DA, Cai S, Bowen DM, Kim Y, Pajerowski JD, et al. (2009) Polymersome carriers: from self-assembly to siRNA and protein therapeutics. Eur J Pharm Biopharm 71: 463-474.

9. http://www.sciencedirect.com/science/journal/09396411/56/1

10. Scott LC, Yao JC, Benson AB, Thomas AL, Falk S, et al. (2009) A Phase II Study of Pegylatedcamptothecin (Pegamotecan) in the Treatment of Locally Advanced and Metastatic Gastric and Gastro-Oesophageal Junction Adenocarcinoma. Cancer Chemother. Pharmacol 63: 363-370.

11. Jijun F, Lishuang X, Xiaoli W, Shu Z, Xiaoguang T, et al. (2011) Nimodipine (NM) tablets with high dissolution containing NM solid dispersions prepared by hot-melt extrusion. Drug Dev Ind Pharm 37: 934-944.

12. He H, Yang $R$, Tang $X(2010)$ In vitro and in vivo evaluation of fenofibrate solid dispersion prepared by hot-melt extrusion. Drug Dev Ind Pharm 36: 681-687.

13. (2010) Polymers for Pharmaceutical Applications. Lubrizol Pharmaceutical Bulletin 1; Lubrizol: Wickliffe, OH, USA.

14. Lammers $T$ (2010) Improving the efficacy of combined modality anticancer therapy using HPMA copolymer-based nanomedicine formulations. Adv Drug Deliv Rev 62: 203-230.

15. Nowotnik DP, Cvitkovic E (2009) ProLindac (AP5346): a review of the development of an HPMA DACH platinum Polymer Therapeutic. Adv Drug Deliv Rev 61: 1214-1219.

16. Zheng C, Qiu L, Zhu K (2009) Novel Polymersomes Based on Amphiphilic Graft 
Citation: Jain R, Panday A (2015) A Review of Kinetics of Nanoparticulated Delayed Release Formulations. J Nanomed Nanotechnol 6: 304 doi:10.4172/2157-7439.1000304

Polyphosphazenes and Their Encapsulation of Water-Soluble Anti-Cancer Drug. Polymer 50: 1173-1177

17. Lu DR, Xiao CM, Xu SJ (2009) Starch-Based Completely Biodegradable Polymer Materials. Express Polym Lett 3: 366-375.

18. Onofre FO, Wang YJ (2010) Hydroxypropylated starches of varying amylose contents as sustained release matrices in tablets. Int J Pharm 385: 104-112.

19. Rajendran L, Knölker HJ, Simons K (2010) Subcellular targeting strategies for drug design and delivery. Nat Rev Drug Discov 9: 29-42.

20. Miller RA, Chu Q, Xie J, Foretz M, Viollet B, et al. (2013) Biguanides suppress hepatic glucagon signaling by decreasing production of cyclic AMP. Nature 3494: 256-260

21. Prizment AE, Gross M, Rasmussen-Torvik L, Peacock JM, Anderson KE (2012) Genes related to diabetes may be associated with pancreatic cancer in a population-based case-control study in Minnesota. Pancreas 41: 50-53.

22. Anumolu R, Gustafson JA, Magda JJ, Cappello J, Ghandehari H, et al. (2011) Fabrication of highly uniform nanoparticles from recombinant silk-elastin-like protein polymers for therapeutic agent delivery. ACS Nano 5: 5374-5382.

23. Kamboj S, Gupta GD (2009) Matrix Tablets: An Important Tool for Oral Controlled-Release Dosage Forms. Pharmainfo net 7.

24. Brahmankar DM, Jaiswal SB (2009) Biopharmaceutics and Pharmacokinetics: Pharmacokinetics. $2^{\text {nd }}$ Edtn, Vallabh Prakashan, Delhi, India.

25. Diebold Y, Calonge M (2010) Applications of nanoparticles in ophthalmology. Prog Retin Eye Res 29: 596-609.

26. Gregory AE, Titball R, Williamson D (2013) Vaccine delivery using nanoparticles Front Cell Infect Microbiol 3: 13

27. Gardouh AR, Gad S, Hassan M (2013) Ghonaim,Mamdouh M. Ghorab, Design and Characterization of Glyceryl Monostearate Solid Lipid Nanoparticles Prepared by High Shear Homogenization. British Journal of Pharmaceutical Research 3: 326-346.

28. Shah M, Agrawal YK, Garala K, Ramkishan A (2012) Solid lipid nanoparticles of a water soluble drug, ciprofloxacin hydrochloride. Indian J Pharm Sci 74: 434-442.

29. Rachmawati H, Herawati DR, Tarini S (2010) Preparation and Characterization of Folic Acid-Encapsulated Solid Lipid Nanoparticle. Jurnal Nanosains \& Nanoteknologi 3.

30. Padhye SG, Nagarsenker MS1 (2013) Simvastatin Solid Lipid Nanoparticles for Oral Delivery: Formulation Development and In vivo Evaluation. Indian J Pharm Sci 75: 591-598.

31. Ekambaram P, Sathali AH, Priyanka K (2012) Solid Lipid Nanoparticles: A Review. Scientific Reviews and Chemical. Communication 2 Suppl 1: 80-102.

32. Bauer BJ, Fagan JA, Hobbie EK, Chun J, Bajpai V (2008) Chromatographic Fractionation of SWNT/DNA Dispersions with On-Line Multi-Angle Light Scattering. J Phys Chem C 112: 1842-1850.

33. Cole KD, Pease LF, Tsai DH, Singh T, Lute S, et al. (2009) Particle Concentration Measurement of Virus Samples Using Electrospray Differential Mobility Analysis and Quantitative Amino Acid Analysis. J Chromatogr A 1216: 5715-5722.

34. Elzey S, Grassian VH (2010) Agglomeration, Isolation and Dissolution of Commercially Manufactured Silver Nanoparticles in Aqueous Environments. J Nanopart Res 12: 1945-1958.

35. Hollertz M, Elliott JT, Lewis J, Mansfield ER, Whetten WD, et al. (2011) Structural Differentiation of Oxytocin in Cyclical and Linear Conformations Using High Resolution Differential Mobility Analysis. Anal Chem.

36. Kang H, Clarke ML, Pease LF, DePaoli Lacaerda SH, Karim A, et al. (2011) Analysis of the Optical Properties of Clustered Colloidal Quantum Dots by the Chi-Square Distribution of the Fluorescence Lifetime Curves.

37. Kang H, Clarke ML, DePaoli Lacaerda SH, Pease III LF, Hwang J (2012) Multimodal Optical Studies of Single and Clustered Colloidal Quantum Dots Towards the Long-term Performance Evaluation of Optical Properties of Quantum Dot-included Molecular Imaging Phantoms. Biomed Opt Express 3: 1312.

38. Kapellios S, Karamanou MF, Sardis M, Aivaliotis A, Economou S, et al. (2011) Using Nanoelectrospray Ion Mobility Spectrometry (GEMMA) to Determine the Size and Relative Molecular Mass of Proteins and Protein Assemblies: A Comparison with MALLS and QELS. Anal Bioanal Chem 399: 2421-2433.
39. Kim SK, Ha T, Schermann JP (2010) Advances in mass spectrometry for biological science. Phys Chem Chem Phys 12: 13366-13367.

40. Knapman TW, Morton VL, Stonehouse NJ, Stockley PG, Ashcroft AE (2010) Determining the Topology of Virus Assembly Intermediates Using lon Mobility Spectrometry-Mass Spectrometry. Rapid Commun Mass Spectrom 24: 3033-3042.

41. Li M, Guha S, Zangmeister RA, Tarlov MJ, Zachariah MR (2011) Quantification and Compensation of Nonspecific Analyte Aggregation in Electrospray Sampling. Aerosol Sci Technol 45: 849-860.

42. Pease III LF, Tsai DH, Fagan JA, Bauer BJ, Zangmeister RA, et al., (2009) Length Distributions of Single Wall Carbon Nanotubes in Aqueous Suspensions Measured by Electrospray-Differential Mobility Analysis. Small 5: 242894-290.

43. Pease LF, Tsai DH, Hertz JL, Zangmeister RA, Zachariah MR, et al. (2010) Packing and size determination of colloidal nanoclusters. Langmuir 26: 1138411390.

44. Pease LF (2012) Physical analysis of virus particles using electrospray differential mobility analysis. Trends Biotechnol 30: 216-224.

45. Dora IA, Sylvaine FA, Faria N, Poots LK, Tagmount MA, et al. (2014) Nanoparticulate iron(III) oxo-hydroxide delivers safe iron that is well absorbed and utilised in humans. Nanomedicine: Nanotechnology, Biology, and Medicine 10: $1877-1886$.

46. Chan SY, Chung YY, Cheah XZ, Eryn YLT, Quah J (2015) The characterization and dissolution performances of spray dried solid dispersion of Ketoprofen in hydrophilic carriers. Asian Journal of Pharmaceutical Sciences.

47. Sharma SK, MohanS, Jaimini M (2014) Formulation and In-Vitro Evaluation of Modified Release Tablets of Gliclazide (Ant diabetic Drug). International Journal of Pharmacy and Pharmaceutical Sciences.

48. http://en.wikipedia.org/wiki/Quantum_dot

49. Ummadi S, Shravani B, Rao NGR, Reddy MS, Nayak BS (2015) Overview on Controlled Release Dosage Form. International Journal of Pharma Sciences 3: 258-269.

50. Parmara K, Patelb J, Shetha N (2015) Self nano-emulsifying drug delivery system for Embelin: Design, characterization and in-vitro studies. Asian Journal of Pharmaceutical Sciences.

51. Lina N, Huanga J, Changb PR, Fengc L, Yud J (2011) Effect of polysaccharide nanocrystals on structure, properties, and drug release kinetics of alginatebased microspheres. Colloids and Surfaces B: Biointerfaces 85: 270-279.

52. Hadi MA, Azharuddin Md, Rao AS, Rao UV, Sirisha Y (2014) Surface Response Methodology for Development And Optimization Of Naproxen Sustained Release Tablets. Asian Journal of Pharmaceutical and Clinical Research 8 : 125-133.

53. Sandeep SK, Jain R, Pandey A (2015) Nanosuspension formulation to improve the dissolution rate of clonazepam. International Journal of Advanced Research 3: $588-591$. 